Supporting information for

\title{
Self-Assembly and Photo-Induced Spindle-Toroid Morphology Transition of Macromolecular Double-Brushes with Azobenzene Pendants
}

Binbin Xu, Hongyu Qian, Shaoliang Lin*

Shanghai Key Laboratory of Advanced Polymeric Materials, Key Laboratory for

Ultrafine Materials of Ministry of Education, School of Materials Science and Engineering, East China University of Science and Technology, Shanghai 200237, China

* Corresponding author: E-mail: slin@ecust.edu.cn (Tel: +86-21-64251011). 


\section{Experimental Section}

\section{Materials}

2,2'-Azobis(isobutyronitrile) (AIBN, Aldrich, 98\%) was recrystallized from anhydrous ethanol twice. Copper(I) bromide (CuBr, Aldrich, 98\%) was purified by stirring overnight over $\mathrm{CH}_{3} \mathrm{COOH}$ at room temperature, followed by washing with ethanol, diethyl ether and acetone prior to drying at $40^{\circ} \mathrm{C}$ in vacuo for one day. Tetrahydrofuran (THF, Aldrich, 99.9\%) and toluene (Aldrich, 99.8\%) were dried over $\mathrm{CaH}_{2}$ and distilled from sodium and benzophenone under $\mathrm{N}_{2}$ prior to use. Br-acrylatealkyne trifunctional monomer, ${ }^{1}$ cumyl dithiobenzoate $(\mathrm{CDB}),{ }^{2}$ PEO-N ${ }_{3}\left(M_{\mathrm{n}}=425\right.$ $\mathrm{g} / \mathrm{mol})^{3}$ and 6-(4-butyl-4'-oxyazobenzene) hexyl acrylate $(\mathrm{Azo})^{4}$ were synthesized according to previous reports. 1,1,4,7,10,10-Hexamethyl-triethylenetetramine (HMTETA, Aldrich, 97\%) and N,N-dimethylformamide (DMF, TCI, 99.5\%) were used as received. Other reagents that were not specially mentioned were analytically pure and used without further purification.

For self-assembly experiments of asymmetric molecular double-brushes (MDBs), ultrapure water with a specific resistivity of $18.2 \mathrm{M} \Omega \cdot \mathrm{cm}$ was used. A dialysis bag (Membra-cel, 3500 Dalton cutoff) was provided by Serva Electrophoresis GmbH.

\section{Instrumentation}

All NMR analyses were performed on a MERCURY plus 400 spectrometer (Varian, Inc., USA) in $\mathrm{CDCl}_{3}$ and $\mathrm{CD}_{2} \mathrm{Cl}_{2}$; tetramethylsilane $\left({ }^{1} \mathrm{H} \mathrm{NMR}\right)$ and $\mathrm{CDCl}_{3}$ $\left({ }^{13} \mathrm{C} \mathrm{NMR}\right)$ were used as internal standards. Relative molecular weights and molecular 
weight distributions were measured by a conventional gel permeation chromatography (GPC) system equipped with a Waters 1515 Isocratic HPLC pump, a Waters 2414 refractive index detector and a set of Waters Styragel columns (HR3 (500-30,000), HR4 (5,000-600,000), and HR5 (50,000-4,000,000), 7.8×300 mm, particle size $5 \mu \mathrm{m}$ ). GPC measurements were carried out at $35^{\circ} \mathrm{C}$ using $\mathrm{THF}$ as eluents with a flow rate of $1.0 \mathrm{~mL} / \mathrm{min}$. The system was calibrated with linear poly(methyl methacrylate) standards. The photo-isomerization was induced by irradiation with a high-intensity lamp (Uvata UP114). The UV-Vis spectra of the samples were measured over different irradiation time intervals using a UV-Vis spectrophotometer (UV-2550 SHIMADZU). Fluorescence spectra were recorded on a fluorolog-3-P fluorescence spectrophotometer with a band width of $3 \mathrm{~nm} .350 \mathrm{~nm} \mathrm{UV}$ light was used as the excitation. Differential scanning calorimetry (DSC) was performed on a TA Q200 DSC instrument in $\mathrm{N}_{2}$ with a heating rate of $10{ }^{\circ} \mathrm{C} \mathrm{min}^{-1}$.

The structures of the aggregates were characterized by dynamic light scattering (DLS) and microscopes, including transmission electron microscopy (TEM), atomic force microscopy (AFM) and scanning electron microscopy (SEM). Radius of hydrodynamic measurements $\left(R_{\mathrm{h}}\right)$ were recorded by DLS at a scattering angle of $90^{\circ}$ on a commercial laser light scattering spectrometer (ALV/CGS-5022) equipped with an ALV-High QE APD detector and an ALV-5000 digital correlator using a He-Ne laser (the wavelength $\lambda=632.8 \mathrm{~nm}$ ) as light source. TEM observation was carried on JEM-1400F instrument (JEOL) with the accelerating voltage of $200 \mathrm{kV}$. The samples were prepared by dropping the solution onto a copper grid coated with carbon film. 
SEM measurements were performed on a HITACHI S-4800 at an accelerating voltage of $15.0 \mathrm{kV}$. The samples were prepared by dropping the aggregates' solution onto a silicon wafer. The samples were sputtered by gold before observation. AFM images were taken by a JPK NanoWizard Sense system in the AC mode of dropping the aggregates' solution onto a silicon wafer.

\section{RAFT homopolymerization of Br-acrylate-alkyne trifunctional monomer}

CDB (26.4 mg, $0.097 \mathrm{mmol})$ and AIBN (5.3 mg, $0.033 \mathrm{mmol})$ were first added to a $10 \mathrm{~mL}$ Schlenk flask (flame-dried under vacuum prior to use) sealed with a rubber septum for degassing and kept under $\mathrm{N}_{2}$. Next, Br-acrylate-alkyne $(0.80 \mathrm{~g}, 2.91 \mathrm{mmol})$ and dry toluene $(0.9 \mathrm{~mL})$ were added via a gastight syringe. The flask was degassed by three cycles of freeze-pump-thaw followed by immersing the flask into an oil bath set at $70^{\circ} \mathrm{C}$. The polymerization was terminated by immersing the flask into liquid $\mathrm{N}_{2}$ after $20 \mathrm{~h}$. The solution was precipitated into cold $n$-hexane. The crude product was purified by repeated dissolution and precipitation followed by drying in vacuo overnight to give $0.52 \mathrm{~g}$ of pink powder with a $65 \%$ yield. AIBN was used to remove the dithiobenzoate moiety of the polymer at $65^{\circ} \mathrm{C}$ in $\mathrm{THF}$ according to a previous report. ${ }^{5} 0.45 \mathrm{~g}$ of white powder, poly(Br-acrylate-alkyne) 1 bifunctional macro-agent, was obtained after drying in vacuo overnight. Both the ATRP-initiating sites and click reaction sites were preserved during the polymerization (the integral area ratio between the signal of methyl and alkyne is 3 from NMR analysis) according to our

previous report. ${ }^{1} \mathrm{GPC}: M_{\mathrm{n}}=5,600 \mathrm{~g} / \mathrm{mol}, M_{\mathrm{w}} / M_{\mathrm{n}}=1.35 .{ }^{1} \mathrm{H} \mathrm{NMR}\left(\mathrm{CDCl}_{3}\right): \delta(\mathrm{ppm})$ : 
$1.89\left(3 \mathrm{H}, \mathrm{CH}_{3} \mathrm{CHBr}\right), 2.03\left(2 \mathrm{H}, \mathrm{CH}_{2} \mathrm{C}\right) 2.60\left(1 \mathrm{H}, \mathrm{OCH}_{2} \mathrm{CCH}\right), 4.26\left(1 \mathrm{H}, \mathrm{CH}_{3} \mathrm{CHBr}\right)$, $4.50\left(2 \mathrm{H}, \mathrm{CH}_{2} \mathrm{CCH}_{2} \mathrm{O}_{2} \mathrm{C}\right), 4.62\left(2 \mathrm{H}, \mathrm{COOCH}_{2} \mathrm{CCH}\right), 7.15-7.36\left(5 \mathrm{H}\right.$, phenyl). ${ }^{13} \mathrm{C}$ NMR $\left(\mathrm{CDCl}_{3}\right): \delta(\mathrm{ppm}): 21.5\left(\mathrm{CH}_{3} \mathrm{CHBr}\right), 27.4\left(\mathrm{CH}_{2} \mathrm{C}\right), 38.5\left(\mathrm{CH}_{2} \mathrm{C}\right), 40.1$ $\left(\mathrm{CH}_{3} \mathrm{CHBr}\right), 48.2\left(\mathrm{CH}_{2} \mathrm{CCH}_{2} \mathrm{O}_{2} \mathrm{C}\right), 53.2\left(\mathrm{COOCH}_{2} \mathrm{CCH}\right), 61.5\left(\mathrm{OCH}_{2} \mathrm{CCH}\right), 66.7$ $\left(\mathrm{OCH}_{2} \mathrm{CCH}\right), 169.7\left(\mathrm{CHCO}_{2}\right), 172.2\left(\mathrm{CCO}_{2}\right)$.

\section{Synthesis of PA-g-PAzo/PEO 2 MDBs}

$\mathrm{CuBr}(8.4 \mathrm{mg}, 0.058 \mathrm{mmol})$, PEO- $\mathrm{N}_{3}\left(M_{\mathrm{n}}=425 \mathrm{~g} / \mathrm{mol}, 125 \mathrm{mg}, 0.29 \mathrm{mmol}-\mathrm{N}_{3}\right.$ group) and poly(Br-acrylate-alkyne) 1 (9 mg, 0.029 mmol ATRP initiating group) were first added to a $50 \mathrm{~mL}$ Schlenk flask (flame-dried under vacuum prior to use) sealed with a rubber septum for degassing and kept under $\mathrm{N}_{2}$. Next, Azo (1.85 g, 4.35 mmol), HMTETA (16 $\mu \mathrm{L}, 0.058 \mathrm{mmol})$, DMF $(12 \mathrm{~mL})$ and THF $(3 \mathrm{~mL})$ were charged via a gastight syringe. The flask was degassed by three cycles of freeze-pump-thaw followed by immersing the flask into an oil bath set at $80^{\circ} \mathrm{C}$. The polymerization and coupling reaction lasted $5.5 \mathrm{~h}$ and were terminated by immersing the flask into liquid $\mathrm{N}_{2}$. The mixture was diluted by THF and passed through an alumina column to remove the residual copper catalyst. The solution was concentrated and precipitated into a mixture of hexane/diethyl ether $(\mathrm{v}: \mathrm{v}=3: 1)$. After repeated purification by dissolving in THF and precipitating in hexane/diethyl ether five times to completely remove the unreacted Azo monomer and PEO- $\mathrm{N}_{3}, 35 \mathrm{mg}$ of PA-g-PAzo/PEO 2 was obtained after drying in vacuo overnight. GPC: $M_{\mathrm{n}}=26,500$

$\mathrm{g} / \mathrm{mol}, M_{\mathrm{w}} / M_{\mathrm{n}}=1.37 .{ }^{1} \mathrm{H}$ NMR $\left(\mathrm{CDCl}_{3}\right): \delta(\mathrm{ppm}): 0.88 \quad\left(\mathrm{CH}_{2} \mathrm{CH}_{2} \mathrm{CH}_{2} \mathrm{CH}_{3}\right.$, 
$\left.\mathrm{CH}_{3} \mathrm{CHCO}_{2}\right), \quad 1.35, \quad 1.59, \quad 1.73 \quad\left(\mathrm{CH}_{2} \mathrm{CH}_{2} \mathrm{CH}_{2} \mathrm{CH}_{3}, \quad \mathrm{CH}_{2} \mathrm{CHCO}_{2}, \quad \mathrm{CH}_{2} \mathrm{CCO}_{2}\right.$, $\left.\mathrm{OCH}_{2} \mathrm{CH}_{2} \mathrm{CH}_{2} \mathrm{CH}_{2} \mathrm{CH}_{2} \mathrm{CH}_{2} \mathrm{O}\right), \quad 2.30\left(\mathrm{CH}_{2} \mathrm{CHCO}_{2}\right), \quad 2.61 \quad\left(\mathrm{CH}_{2} \mathrm{CH}_{2} \mathrm{CH}_{2} \mathrm{CH}_{3}\right), \quad 3.30$ $\left(\mathrm{OCH}_{3}\right), 3.57\left(\mathrm{OCH}_{2} \mathrm{CH}_{2}\right), 3.91,4.02\left(\mathrm{OCH}_{2} \mathrm{CH}_{2} \mathrm{CH}_{2} \mathrm{CH}_{2} \mathrm{CH}_{2} \mathrm{CH}_{2} \mathrm{O}, \mathrm{CH}_{2} \mathrm{CCO}_{2} \mathrm{CH}_{2}\right.$, $\left.\mathrm{CH}_{2} \mathrm{CCH}_{2} \mathrm{OCO}\right), 6.89,7.23,7.75\left(\mathrm{C}_{6} \mathrm{H}_{4} \mathrm{~N}_{2} \mathrm{C}_{6} \mathrm{H}_{4}\right)$.

\section{Turbidity measurement}

A certain amount of THF solution of PA- $g$-PAzo/PEO 2 MDBs $(0.20 \mathrm{mg} / \mathrm{mL})$ was added to a quartz cell. The solution was subjected to UV-vis spectra measurement after every addition of $20 \mu \mathrm{L}$ water. The transmittance of the solution at $680 \mathrm{~nm}$ was recorded to study the turbidity of the solution with different water contents.

\section{Preparation of self-assembled aggregates of MDBs}

The aggregate aqueous solutions were prepared using a dialysis method. The PA-g-PAzo/PEO 2 MDBs was first dissolved in THF with initial concentration of $0.05 \mathrm{mg} \mathrm{mL}^{-1}$ and $0.2 \mathrm{mg} \mathrm{mL}^{-1}$, respectively. Then, the different volume of deionized water was added into a polymer solution at the rate of $1 \mathrm{~mL} / \mathrm{h}$ under slow stirring. Two hours after the addition of deionized water, 9-fold of deionized water was poured into the mixture to quench the aggregate morphology. The aggregate solution was obtained by dialysis against deionized water after 3 days to remove THF. The solution was cast on a copper grid for TEM measurement. 


\section{Effect of storage time on the self-assembled aggregates of MDBs}

To study the effect of storage time on the morphology of MDB system, we first prepared small spindle-1 aggregate solution, then the solution was stored at $30^{\circ} \mathrm{C}$ before morphology and size characterization. At appropriate time intervals, small aliquots were removed from the solution for TEM and DLS analysis.

\section{Photo-isomerization and photo-induced deformation of MDB micelles}

The photo-isomerization of the azo chromophores was induced by irradiation with

a high-intensity lamp (Uvata UP114). For trans-to-cis and cis-to-trans photo-isomerization, the UV-Vis spectra of the samples were measured over different irradiation time intervals at $365 \mathrm{~nm}$ and $450 \mathrm{~nm}$, respectively. In order to study the effect of photo-isomerization of the azo micelles on the aggregate morphologies, MDB micellar solutions were first irradiated using $365 \mathrm{~nm}$ UV light (light intensity was $129 \mathrm{~mW} / \mathrm{cm}^{2}$ ) under stirring in a small vial. After trans-to-cis isomerization was complete, the micellar solution was cast on a copper grid and silicon wafer immediately. The irradiation light at $450 \mathrm{~nm}$ was used in succession for the cis-to-trans recovery. The solution was also cast on a copper grid and silicon wafer for the TEM and SEM measurements, respectively. 
Table S1. Synthesis of poly(Br-acrylate-alkyne) 1 and PA-g-PAzo/PEO 2

\begin{tabular}{cccccc}
\hline Entry & Monomer & Temperature $\left({ }^{\circ} \mathrm{C}\right)$ & $M_{\mathrm{n}, \mathrm{GPC}^{\mathrm{c}}}$ & $\mathrm{Ð}^{\mathrm{c}}$ & Repeat units $^{\mathrm{d}}$ \\
& & $\left(\mathrm{g} \mathrm{mol}^{-1}\right)$ & & \\
\hline $\mathbf{1}^{\mathrm{a}}$ & Br-acrylate-alkyne & 70 & 5,600 & 1.35 & 28 \\
$\mathbf{2}^{\mathrm{b}}$ & PAzo\&PEO & 80 & 26,500 & 1.37 & $13 \& 9$ \\
\hline
\end{tabular}

a Poly(Br-acrylate-alkyne) 1 , AIBN as the initiator and CDB as the CTA, solvent:

toluene. ${ }^{b}$ Feeding ratio: [Azo]:[-N 3$]:[-\mathrm{Br}]:[\mathrm{CuBr}]:[\mathrm{HMTETA}]=150: 10: 1: 2: 2$, $[-\mathrm{C} \equiv \mathrm{CH}]=[-\mathrm{Br}] .{ }^{\mathrm{c}}$ Measured by $\mathrm{GPC}$ at $35{ }^{\circ} \mathrm{C}$ in THF. ${ }^{\mathrm{d}}$ The number of repeat units of Br-acrylate-alkyne, Azo and EO obtained from ${ }^{1} \mathrm{H}$ NMR. 


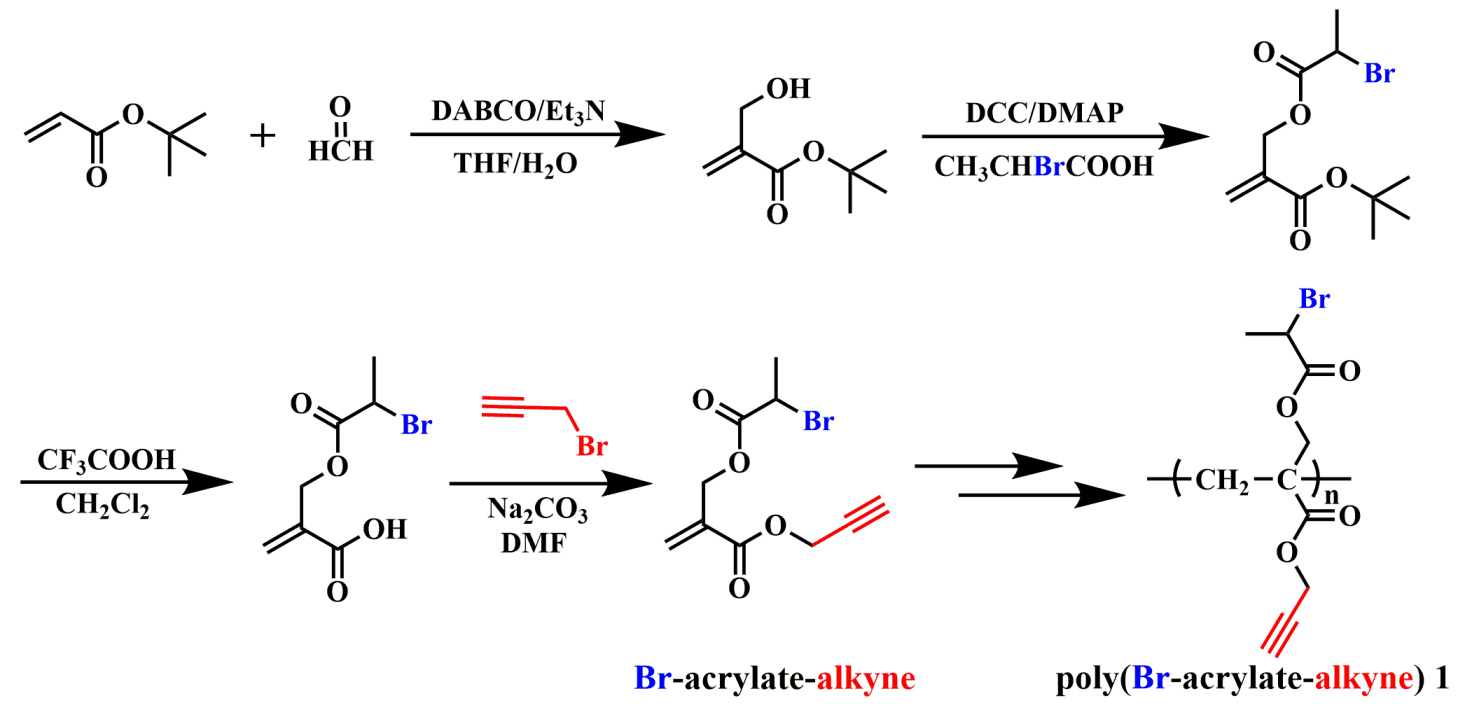

Scheme S1. Synthesis of Br-acrylate-alkyne trifunctional monomer and poly(Br-acrylate-alkyne) 1 bifunctional macro-agent.

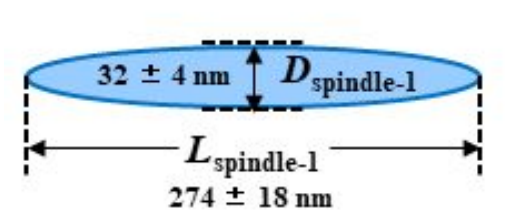

Spindle-1

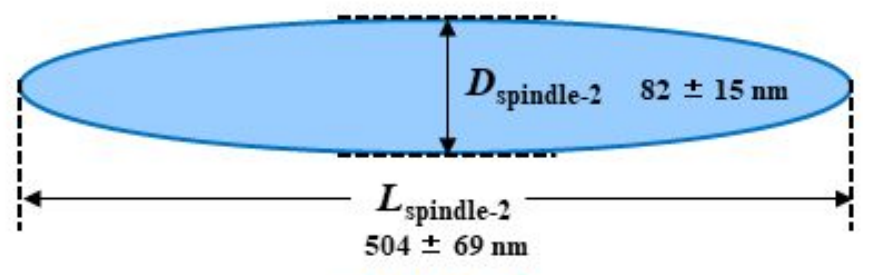

Spindle-2

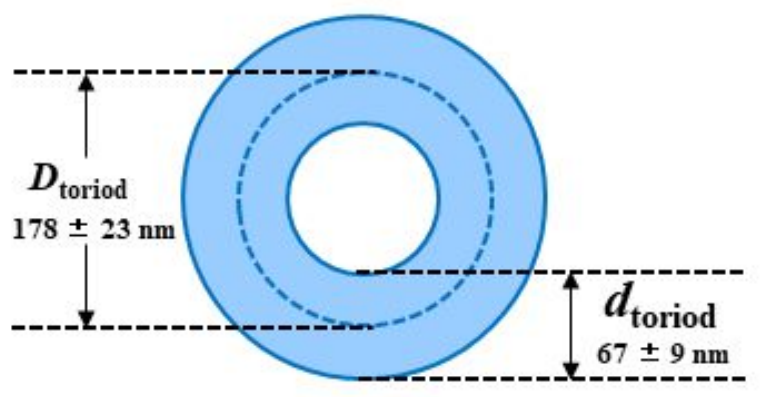

Toroid

Scheme S2. Illustration of the measured sizes of the spindle-like and toroid-2 micelles.

The average length and diameter of the micelles were calculated by measuring more than 150 individual aggregates from TEM images. 
Poly(Br-acrylate-alkyne) $1, M_{\mathrm{n}}=5,600 \mathrm{~g} / \mathrm{mol}$

PA-g-PAzo/PEO 2, $M_{\mathrm{n}}=26,500 \mathrm{~g} / \mathrm{mol}$

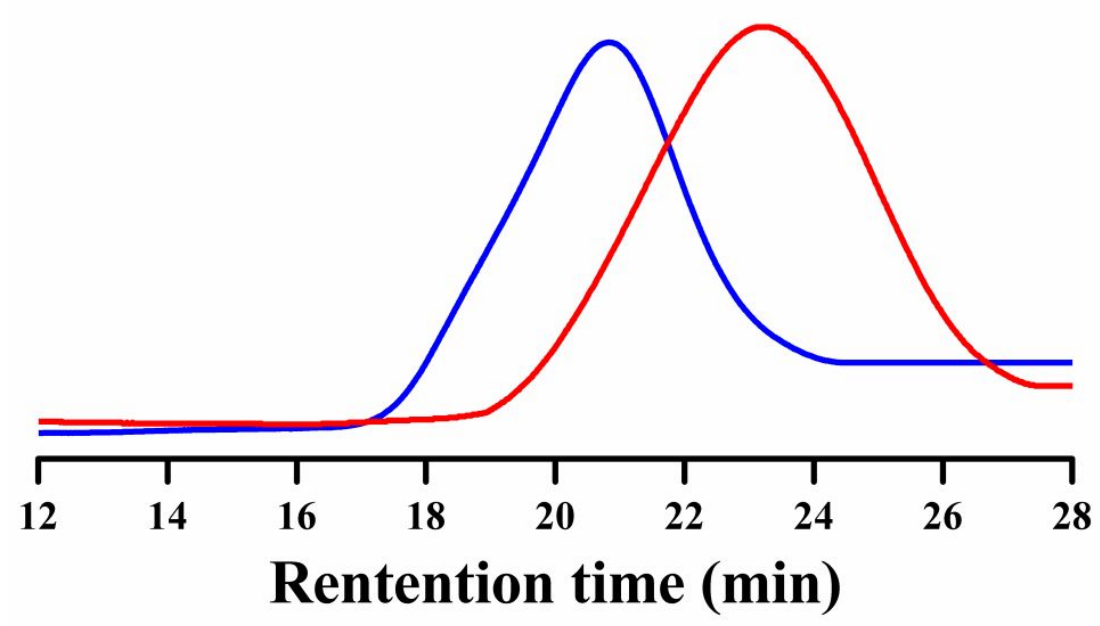

Figure S1. GPC traces of poly(Br-acrylate-alkyne) 1 and PA-g-PAzo/PEO 2 in THF.

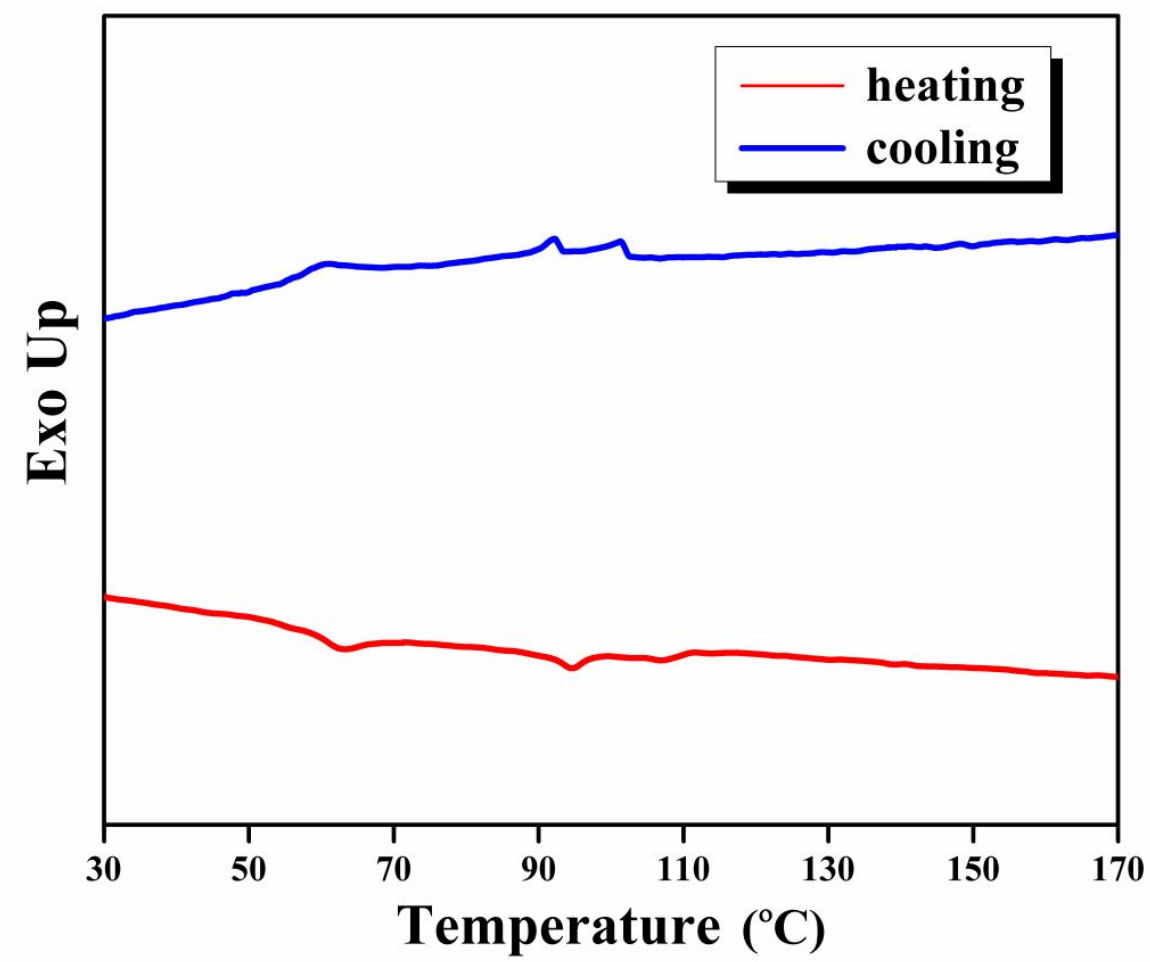

Figure S2. The first cooling and second heating DSC curves of PA-g-PAzo/PEO 2. 


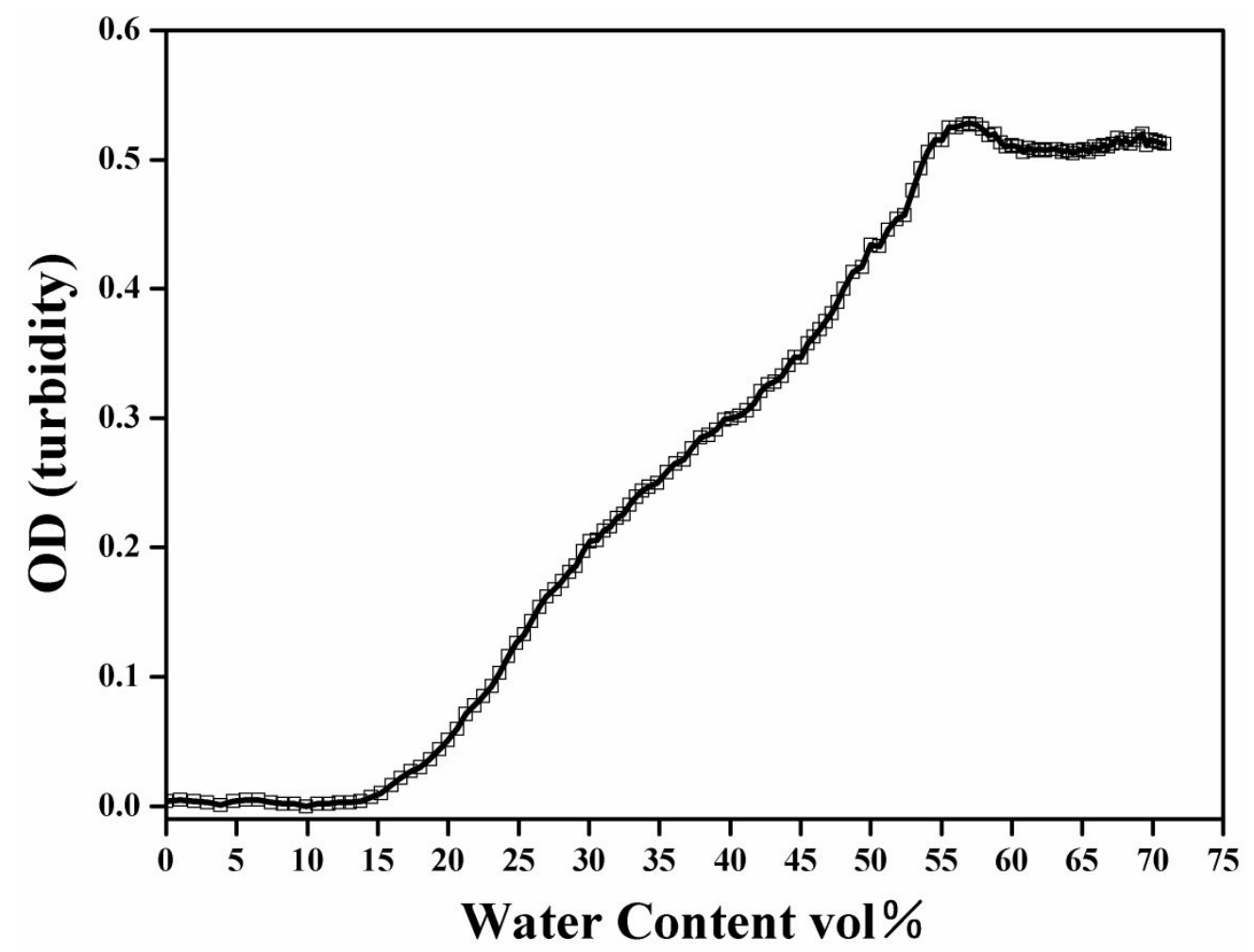

Figure S3. Plots of optical density versus water content for PA-g-PAzo/PEO 2 in THF solutions with the initial concentration of $0.2 \mathrm{mg} / \mathrm{mL}$. 

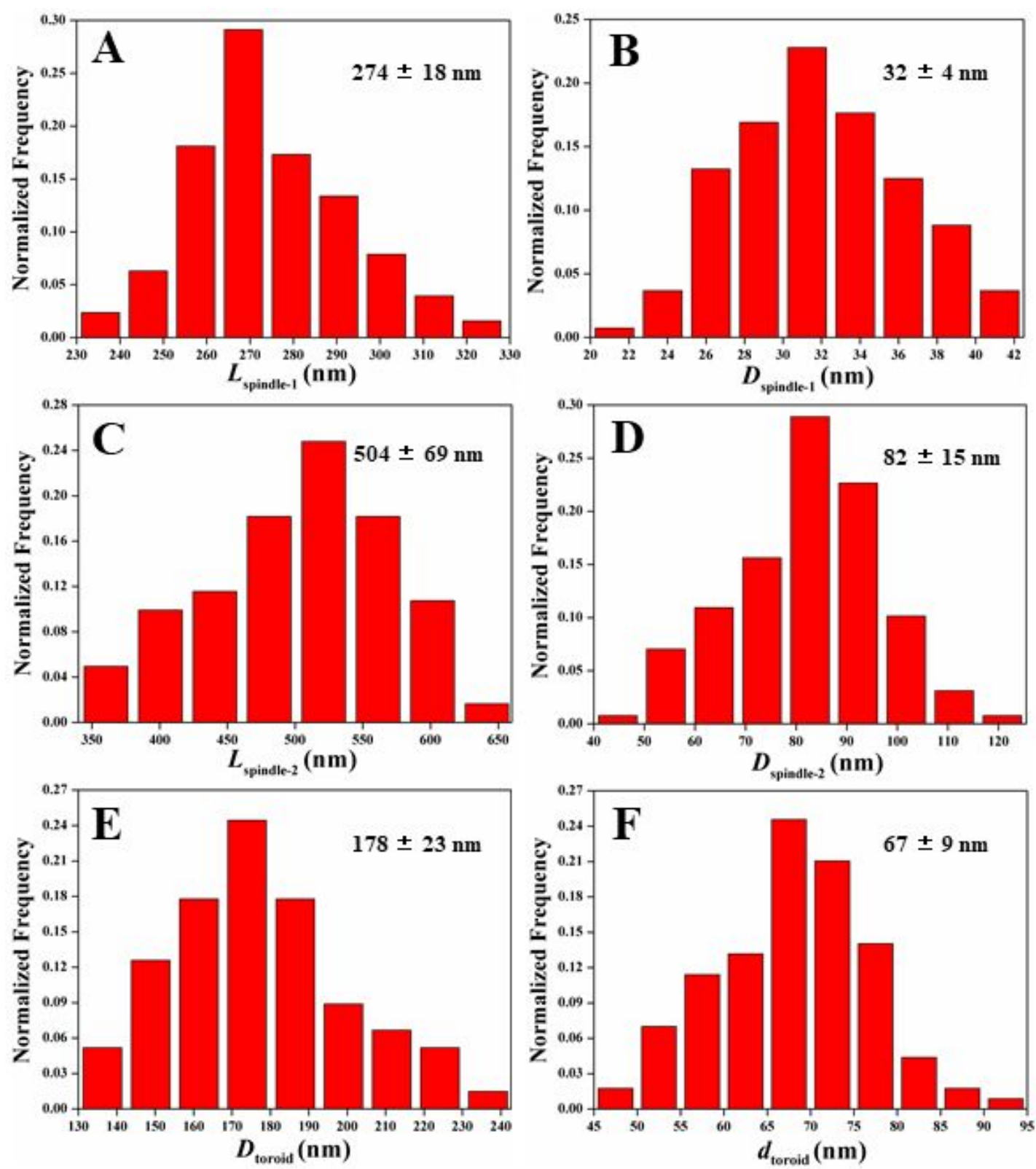

Figure S4. The length (A, defined as $\left.L_{\text {spindle-1 }}\right)$ and diameter (B, $\left.D_{\text {spindle-1 }}\right)$ distribution of spindle-like aggregates formed by $0.2 \mathrm{mg} / \mathrm{mL}$ initial concentration and $30 \mathrm{wt} \%$ water content. The length $\left(\mathrm{C}, L_{\text {spindle-2 }}\right)$ and diameter $\left(\mathrm{D}, D_{\text {spindle-2 }}\right)$ distribution of spindle-like aggregates formed by $0.2 \mathrm{mg} / \mathrm{mL}$ initial concentration and $45 \mathrm{wt} \%$ water content. The diameter distribution of toroid (E, top-to-top diameter, $D_{\text {toriod }}$ ) and the diameter distribution of toroidal spindle $\left(\mathrm{F}\right.$, edge-to-edge distance, $\left.d_{\text {toriod }}\right)$ formed by spindle-2 aggregates upon UV irradiation. 

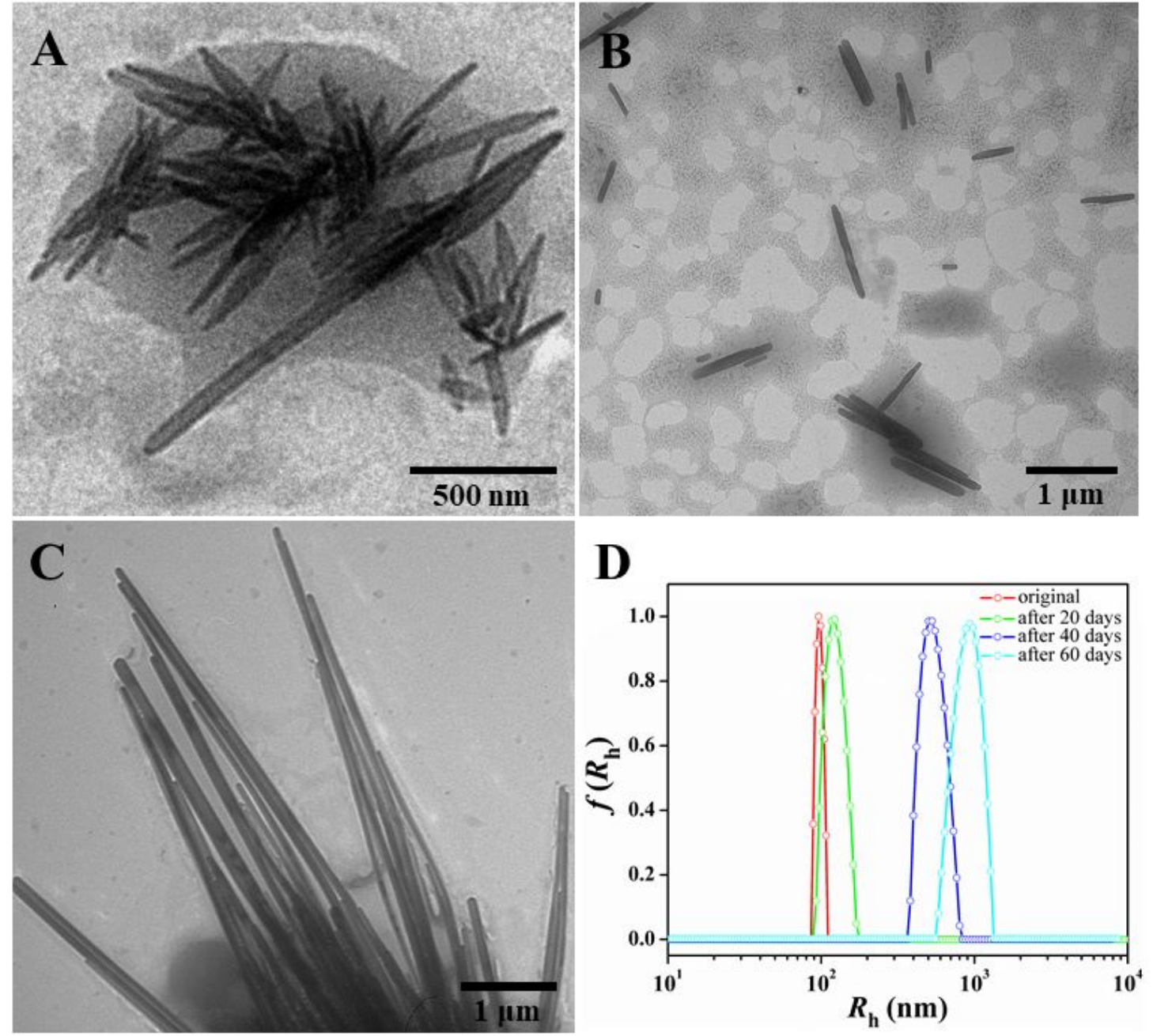

Figure S5. TEM images of PA-g-PAzo/PEO spindle-1 aggregates after storing (A) 20 days, (B) 40 days and (C) 60 days at $30{ }^{\circ} \mathrm{C}$. (D) Hydrodynamic radius $\left(R_{\mathrm{h}}\right)$ distribution of spindle-1 micelles at different times. 

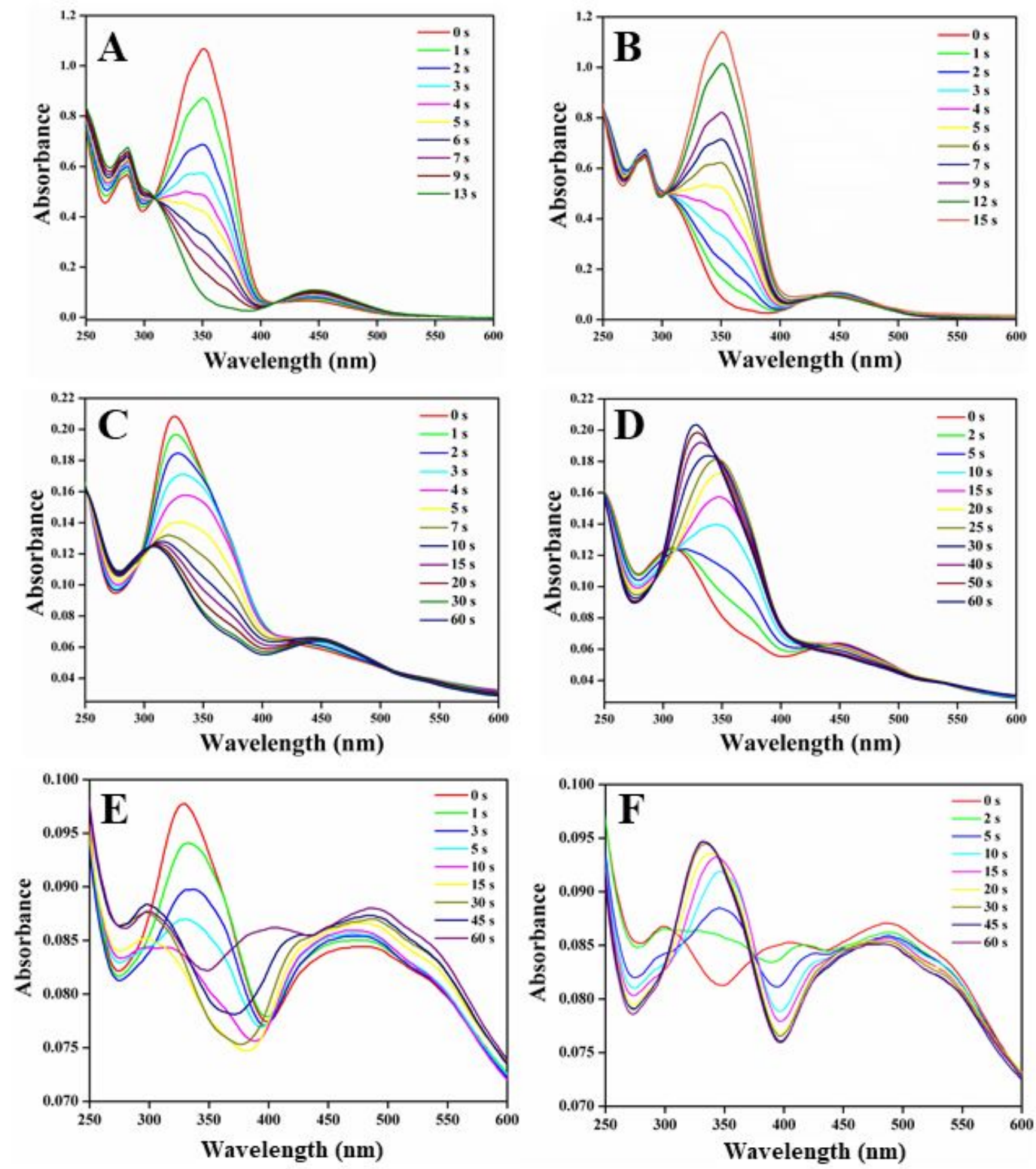

Figure S6. UV-Vis absorption spectra of PA-g-PAzo/PEO in THF and micelle aqueous solution: (A) in THF upon irradiation of $365 \mathrm{~nm}$ light; (B) in THF upon irradiation of $450 \mathrm{~nm}$ light; (C) spindle-1 micelle aqueous solution upon irradiation of $365 \mathrm{~nm}$ light; (D) spindle-1 micelle aqueous solution upon irradiation of $450 \mathrm{~nm}$ light; (E) spindle-2 micelle aqueous solution upon irradiation of $365 \mathrm{~nm}$ light; (F) spindle-2 micelle aqueous solution upon irradiation of $450 \mathrm{~nm}$ light. 


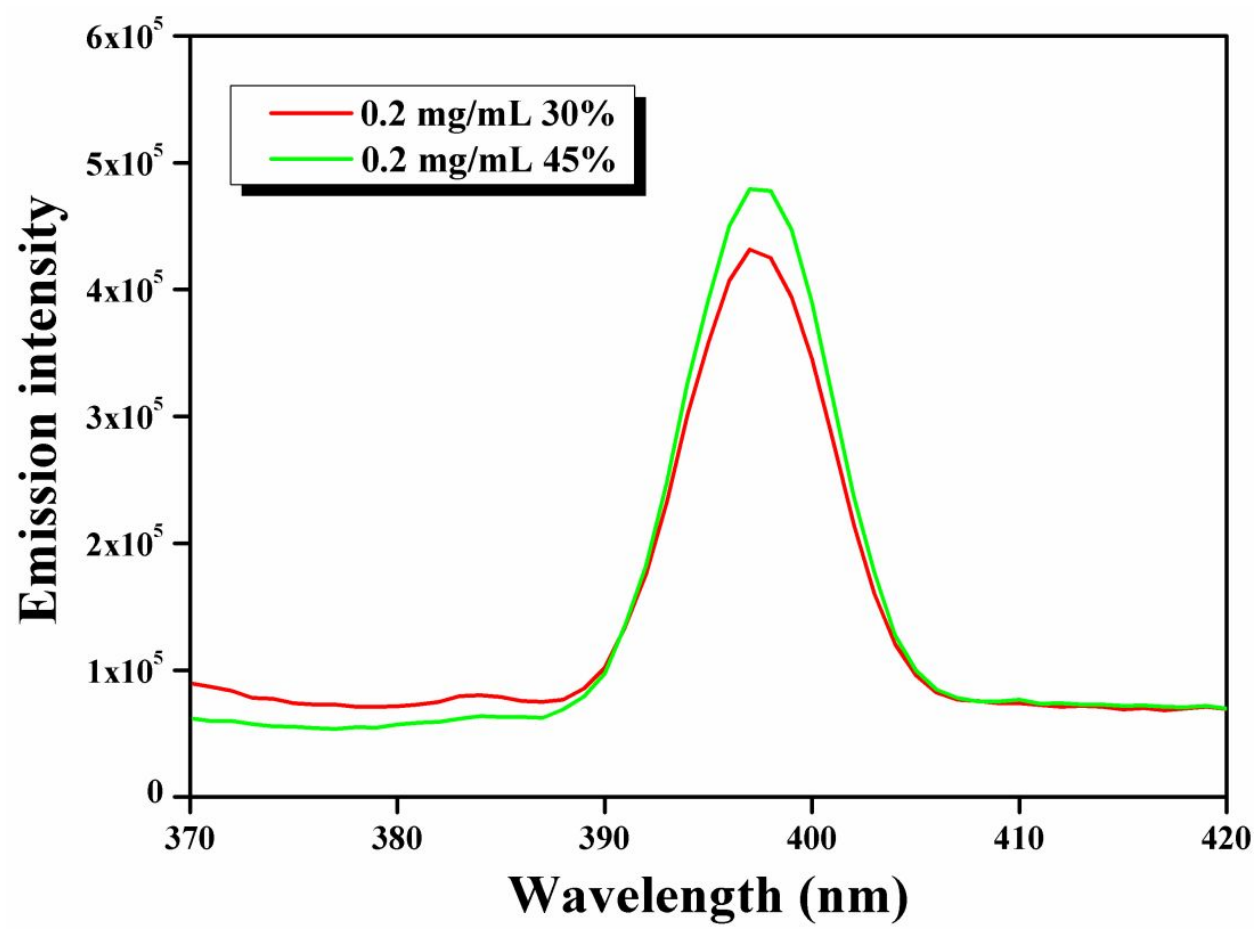

Figure S7. Fluorescence emission (slit: $3 \mathrm{~nm}, \lambda \mathrm{ex}=350 \mathrm{~nm}$ ) of PA-g-PAzo/PEO spindle-1 and spindle-2 micelles in aqueous solution. 

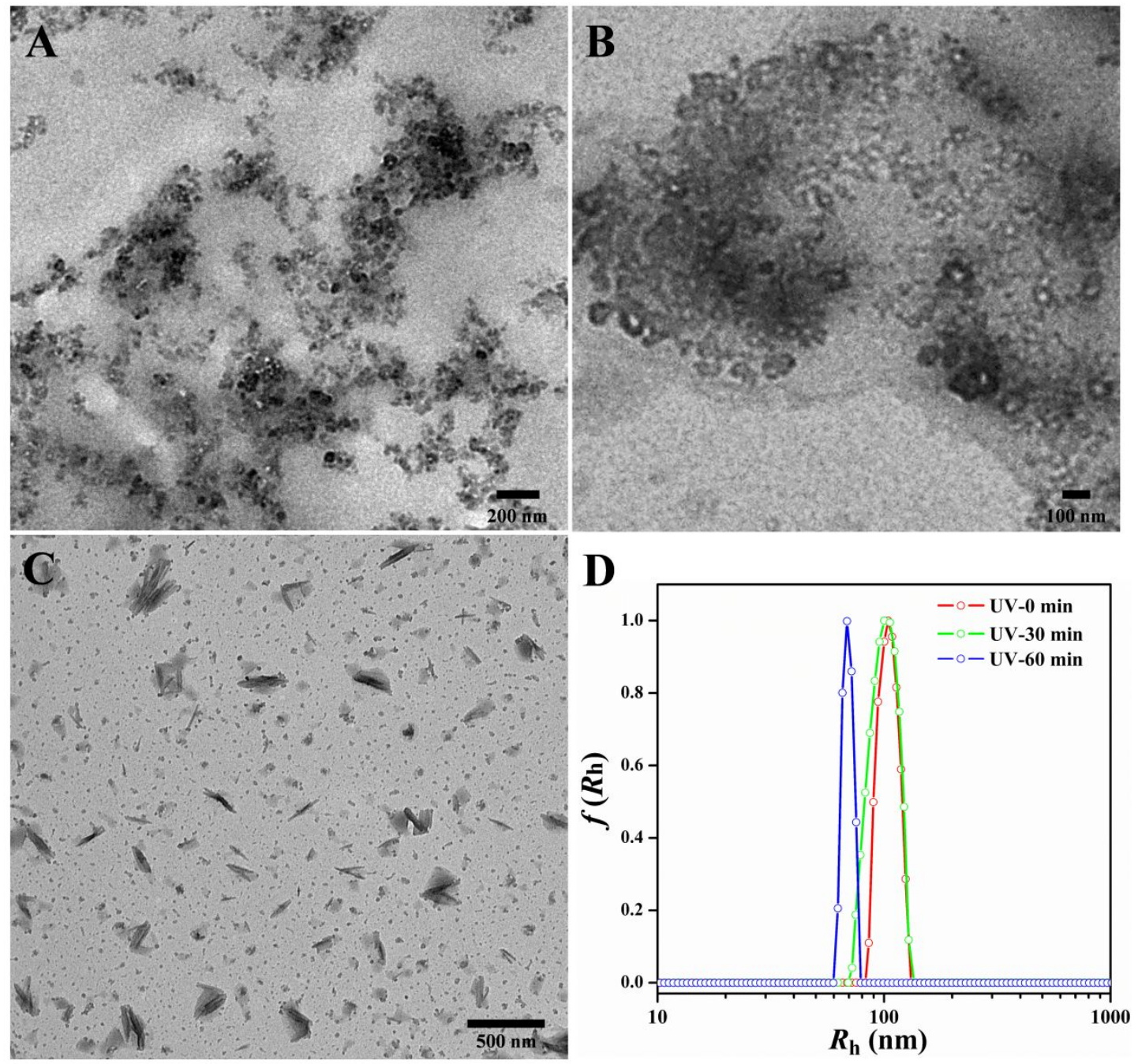

Figure S8. TEM images of PA-g-PAzo/PEO spindle-1 micelles after $365 \mathrm{~nm}$ light irradiation for $1 \mathrm{~h}(\mathrm{~A}$ and $\mathrm{B})$, then upon visible light $(450 \mathrm{~nm})$ for $1 \mathrm{~h}(\mathrm{C})$. (D) Hydrodynamic radius $\left(R_{\mathrm{h}}\right)$ distribution of spindle-1 micelles in water over different irradiation time intervals at $365 \mathrm{~nm}$. 

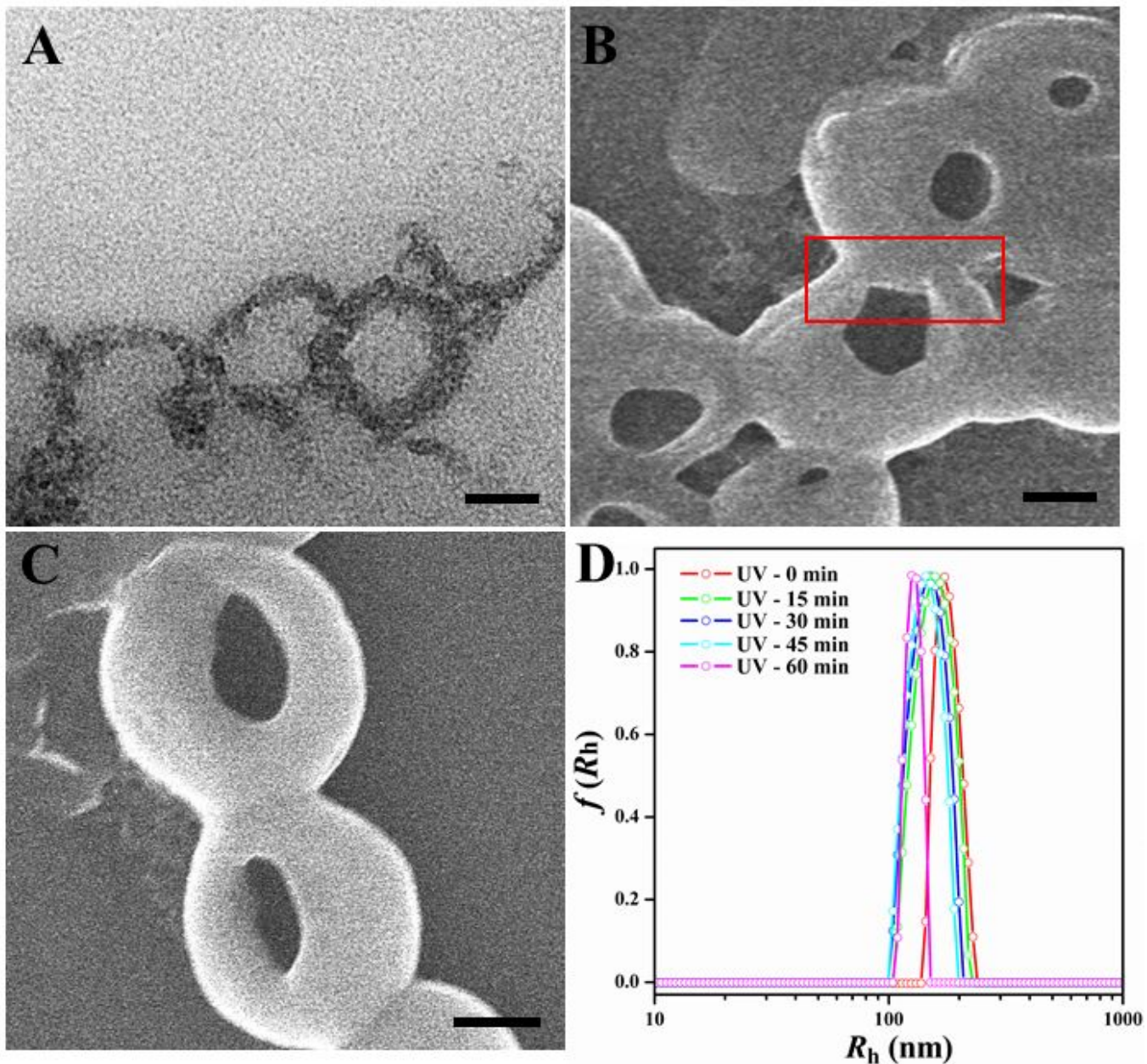

Figure S9. (A) TEM image of PA-g-PAzo/PEO toroid and curved aggregates bended from spindle-2 micelles after $365 \mathrm{~nm}$ light irradiation. SEM images of (B) typical intermediate morphology during the formation of the toroid aggregates and (C) final toroid aggregates. (D) $R_{\mathrm{h}}$ distribution of spindle-2 micelles in water over different irradiation time intervals at $365 \mathrm{~nm}$. Scale bars: $100 \mathrm{~nm}$. 


\section{References}

1. Xu. B.; Feng, C.; Huang, X. A Versatile Platform for Precise Synthesis of Asymmetric Molecular Brush in One Shot. Nat. Commun. 2017, 8, 333.

2. Moad, G.; Chiefari, J.; Chong, Y. K.; Krstina, J.; Mayadunne, R. T. A.; Postma, A.; Rizzardo, E.; Thang, S. H. Living Free Radical Polymerization with Reversible Addition-Fragmentation Chain Transfer (the Life of RAFT). Polym. Int. 2000, 49, 993-1001.

3. Gao, H.; Matyjaszewski, K. Synthesis of Molecular Brushes by "Grafting onto" Method: Combination of ATRP and Click Reactions. J. Am. Chem. Soc. 2007, $129,6633-6639$.

4. Stewart, D.; Imrie, C. T. Synthesis and Characterization of Spin-labelled and Spin-probed Side-chain Liquid Crystal Polymers. Polymer 1996, 37, 3419-3425.

5. Perrier, S.; Takolpuckdee, P.; Mars, C. A. Reversible Addition-Fragmentation Chain Transfer Polymerization: End Group Modification for Functionalized Polymers and Chain Transfer Agent Recovery. Macromolecules 2005, 38, 20332036. 